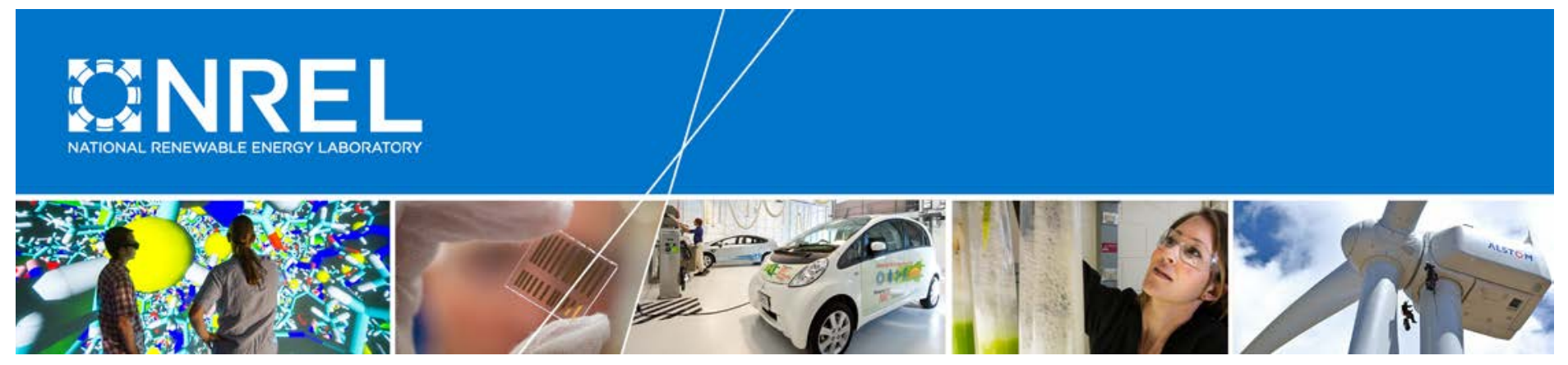

\title{
Photovoltaic Array Field Characterization Report: University of Toledo R1 Arrays
}

Timothy J. Silverman, Peter McNutt, and John Wohlgemuth National Renewable Energy Laboratory

NREL is a national laboratory of the U.S. Department of Energy Office of Energy Efficiency \& Renewable Energy Operated by the Alliance for Sustainable Energy, LLC

This report is available at no cost from the National Renewable Energy Laboratory (NREL) at www.nrel.gov/publications.

Technical Report

NREL/TP-5J00-64998

September 2015 


\section{Photovoltaic Array Field Characterization Report: University of Toledo R1 Arrays}

Timothy J. Silverman, Peter McNutt, and John Wohlgemuth National Renewable Energy Laboratory

Prepared under Task No. SS13.5510

NREL is a national laboratory of the U.S. Department of Energy Office of Energy Efficiency \& Renewable Energy Operated by the Alliance for Sustainable Energy, LLC

This report is available at no cost from the National Renewable Energy Laboratory (NREL) at www.nrel.gov/publications.

National Renewable Energy Laboratory 15013 Denver West Parkway Golden, CO 80401

303-275-3000 • www.nrel.gov

\section{Technical Report}

NREL/TP-5J00-64998

September 2015

Contract No. DE-AC36-08G028308 


\section{NOTICE}

This report was prepared as an account of work sponsored by an agency of the United States government. Neither the United States government nor any agency thereof, nor any of their employees, makes any warranty, express or implied, or assumes any legal liability or responsibility for the accuracy, completeness, or usefulness of any information, apparatus, product, or process disclosed, or represents that its use would not infringe privately owned rights. Reference herein to any specific commercial product, process, or service by trade name, trademark, manufacturer, or otherwise does not necessarily constitute or imply its endorsement, recommendation, or favoring by the United States government or any agency thereof. The views and opinions of authors expressed herein do not necessarily state or reflect those of the United States government or any agency thereof.

This report is available at no cost from the National Renewable Energy Laboratory (NREL) at www.nrel.gov/publications.

Available electronically at SciTech Connect http:/www.osti.gov/scitech

Available for a processing fee to U.S. Department of Energy and its contractors, in paper, from:

U.S. Department of Energy

Office of Scientific and Technical Information

P.O. Box 62

Oak Ridge, TN 37831-0062

OSTI http://www.osti.gov

Phone: 865.576.8401

Fax: 865.576.5728

Email: reports@osti.gov

Available for sale to the public, in paper, from:

U.S. Department of Commerce

National Technical Information Service

5301 Shawnee Road

Alexandria, VA 22312

NTIS http://www.ntis.gov

Phone: 800.553 .6847 or 703.605 .6000

Fax: 703.605.6900

Email: orders@ntis.gov 


\title{
Photovoltaic array field characterization report University of Toledo R1 arrays
}

\author{
Timothy J Silverman, Peter McNutt and John Wohlgemuth
}

November 26, 2014

\section{Introduction}

As part of the Photovoltaics (PV) Service Life Prediction agreement, we visit and characterize PV systems that have been in service for several years. This allows us to assess the condition and performance of PV modules after extended field exposure but before they are decommissioned.

The University of Toledo is a public university with high research activity in Toledo, Ohio. The University was an early collaborator with the company that later became First Solar, Inc, which has major manufacturing and R\&D facilities in nearby Perrysburg, Ohio. The Research and Technology Complex 1 or "R1" building continues to be a center of PV research and an incubator for renewable energy companies.

Four ground-mounted PV arrays are situated on the south side of R1 (Figure 1). The systems were installed in two phases: the two southernmost systems in 2006 and the two northernmost systems in 2014. The systems installed in 2006 are the subject of this report. We visited the site from 2014-09-22 through 2014-09-25.

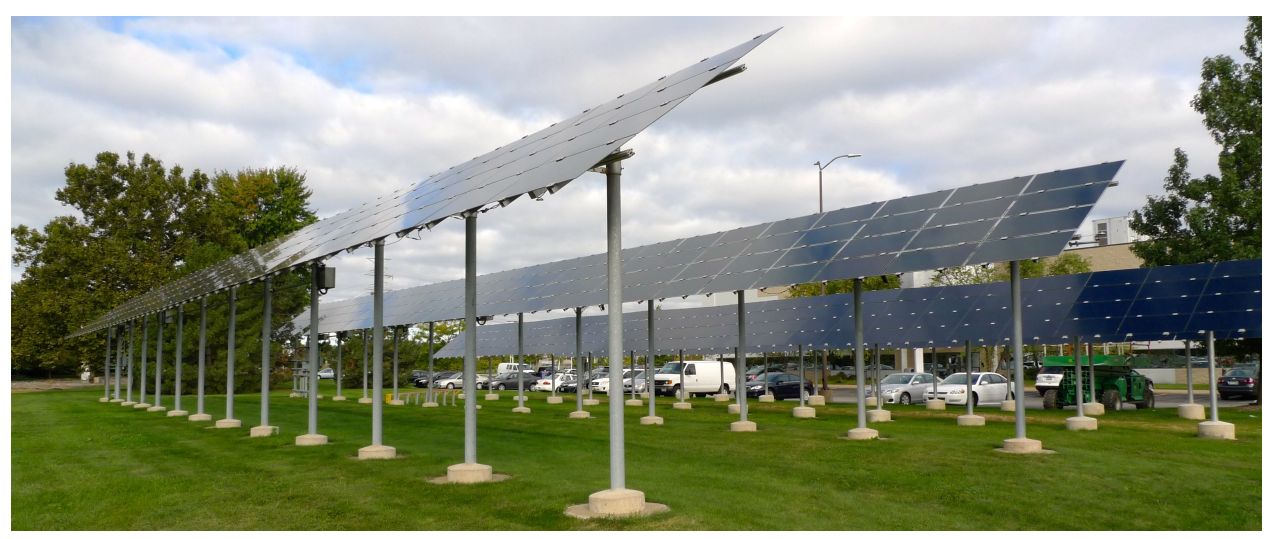

Figure 1: Four ground-mounted CdTe arrays at the University of Toledo R1 building. The two systems in the foreground are the subject of this report.

Each system is a single rack of 108 First Solar model FS-57 CdTe modules. This series 
of modules is informally called "Series 1 " although at the time of its production it was not designated as such. The modules are the $600 \mathrm{~mm} \times 1200 \mathrm{~mm}$ frameless form factor that is typical for First Solar modules. This generation of modules has no edge seal other than the encapsulant in the margin of the laminate. The modules' nameplate power is $57 \mathrm{~W}$, making each system's nameplate capacity $\sim 6.2 \mathrm{~kW}$.

The systems are located at $41.6531^{\circ} \mathrm{N}, 83.6060^{\circ} \mathrm{W}$. Their azimuth is south and their tilt is $35^{\circ}$ above horizontal. The southern edge of the modules is approximately $2.3 \mathrm{~m}$ above the surrounding ground, which is an actively maintained turf lawn.

The southern system ("row 1") has been connected to a Sunny Boy SB6000U $6 \mathrm{~kW}$ inverter since its installation. Series strings of six modules each are all connected in parallel. At some point prior to 2008, a single module in this system was replaced with a newer product.

The northern system ("row 2") was initially wired completely in parallel with a $2 \mathrm{~kW}$ MPP system configured to power an electrolyzer load. When the system's maximum power point exceeded $2 \mathrm{~kW}$, this system clipped it to $2 \mathrm{~kW}$. When the electrolyzer load was less than $2 \mathrm{~kW}$, a dummy load was switched in to dissipate the extra energy [2]. This configuration was used until approximately 2010 , when the electrolyzer was disconnected. There are no records indicating the configuration of the array between 2010 and 2014. The MPPT and dummy load resistor were still located on the site during our visit, but the system might have been at open circuit during this period. In April 2014 this system was reconfigured and connected to a Sunny Boy SB 7000US-12 $7 \mathrm{~kW}$ inverter.

\section{Method}

We performed a formal visual inspection of the modules [4], photographing features of interest. With the system energized, we collected thermal images of every module's front surface and detailed images for areas of interest. Finally, we chose a sample of 42 of the 216 modules and collected I-V characteristics for each.

\section{Results}

\subsection{Visual inspection}

\subsubsection{Nameplate}

Every module's nameplate was nearly illegible because the black text had been bleached white. The chalky texture of the labels had some contrast where lettering once was, enabling the reading of serial numbers at certain angles. The chalky residue appears to have washed down the backs of the modules, leaving streaks behind (Figure 2).

\subsubsection{Soiling}

Immediately before our visit, the site received enough rain to clean the modules. We cleaned a small area of one module to visualize the extent of the soiling that was not washed away by substantial rainfall (Figure 3). On subsequent days, dew on the modules trapped considerable additional soil from a construction site across the street. 


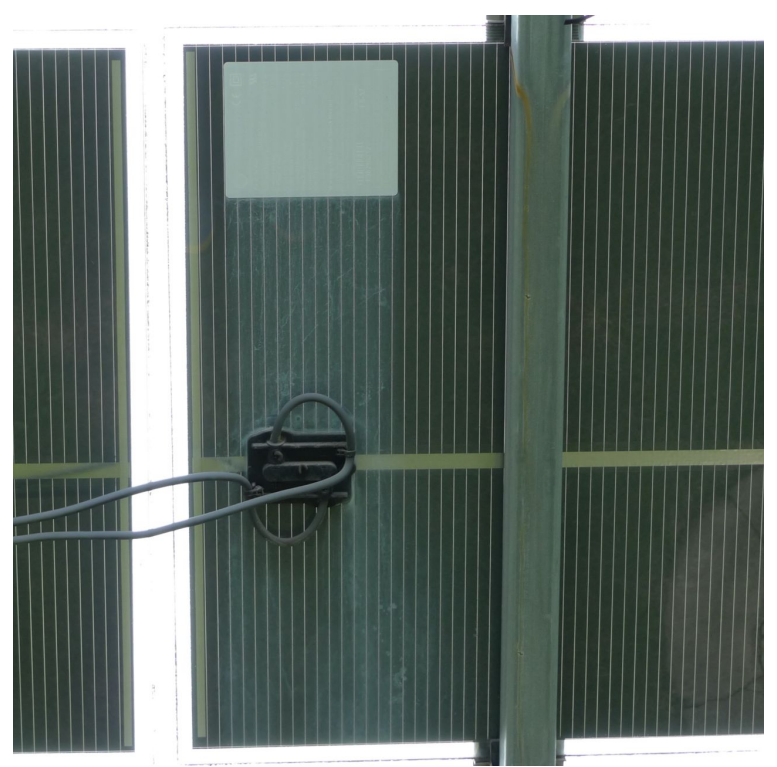

Figure 2: Degraded nameplates on this system left streaks of chalky residue on the backs of modules. Text on the labels was nearly illegible.

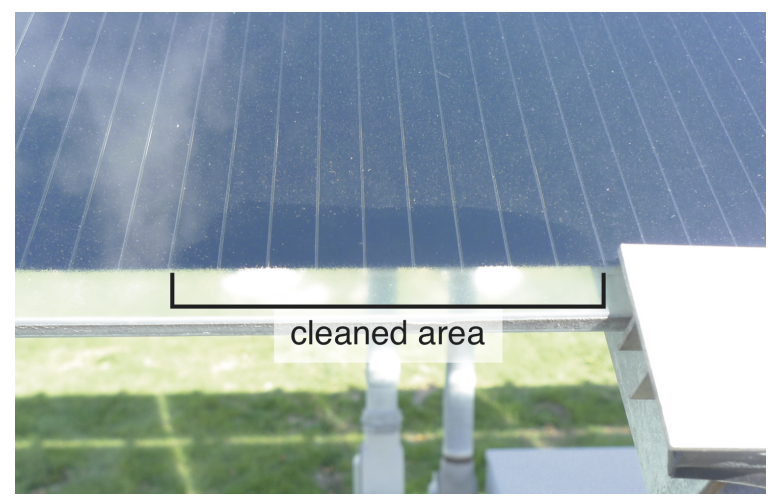

Figure 3: Light soiling present even after substantial rainfall is evident when a small area is cleaned completely. 


\subsubsection{Delamination and discoloration}

The modules use metallic bus tape to connect the junction box to the terminals of the first and last cells. On about $75 \%$ of the modules, a small area of delamination was visible near the serial number, at the intersection of the bus tapes at the junction box end of the module (Figure 4). On some specimens, this delamination extended to areas of the bus tape beyond this intersection, but was always most visible at the intersection. On modules having this delamination, minor discoloration of the encapsulant was visible at the bus tape intersection (Figure 5). Series 3 First Solar modules use a substantially different bus tape design.

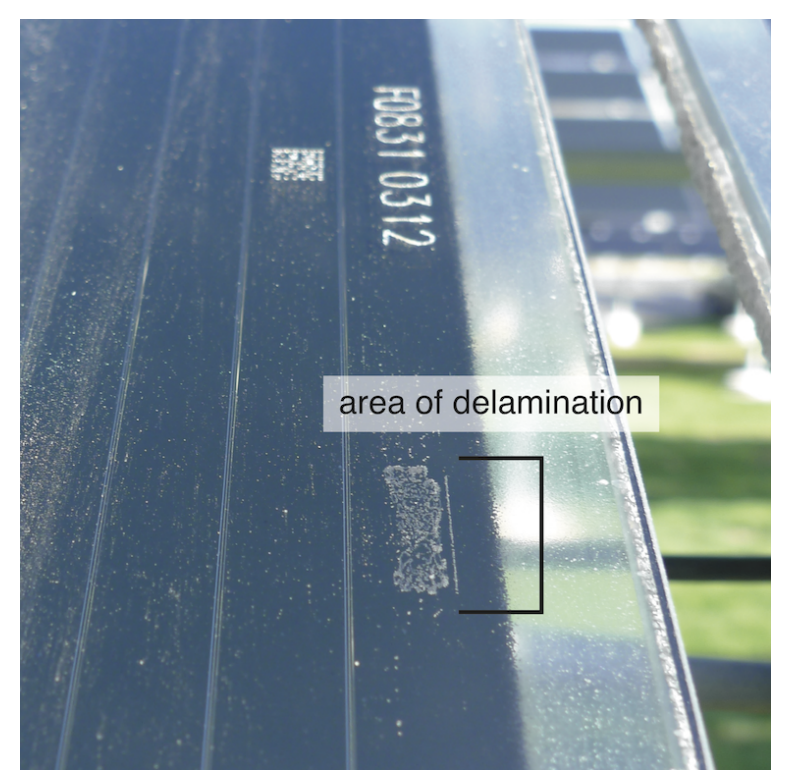

Figure 4: A small area of delamination was present in the same location on about $75 \%$ of modules. This location is the intersection of one pair of bus tapes.

\subsubsection{Encapsulant extrusion}

Most modules had a ring of extruded encapsulant around the periphery of the laminate (Figure 6). This extrudate contained many gas bubbles which, in some cases such as in Figure 6, continued into the margin of the encapsulant. The extrudate was gray in color, presumably due to trapped soil. The out-of-plane thickness of the extrudate was nearly the full thickness of the module and in many cases the outside edge of this extrudate was artificially flat (Figure 7), suggesting that it had been extruded against a form during manufacture and not in the field.

\subsubsection{Glass}

Two modules had broken front glass and one had broken back glass. The modules with broken front glass had visible impact sites and were both located on the array nearest the 


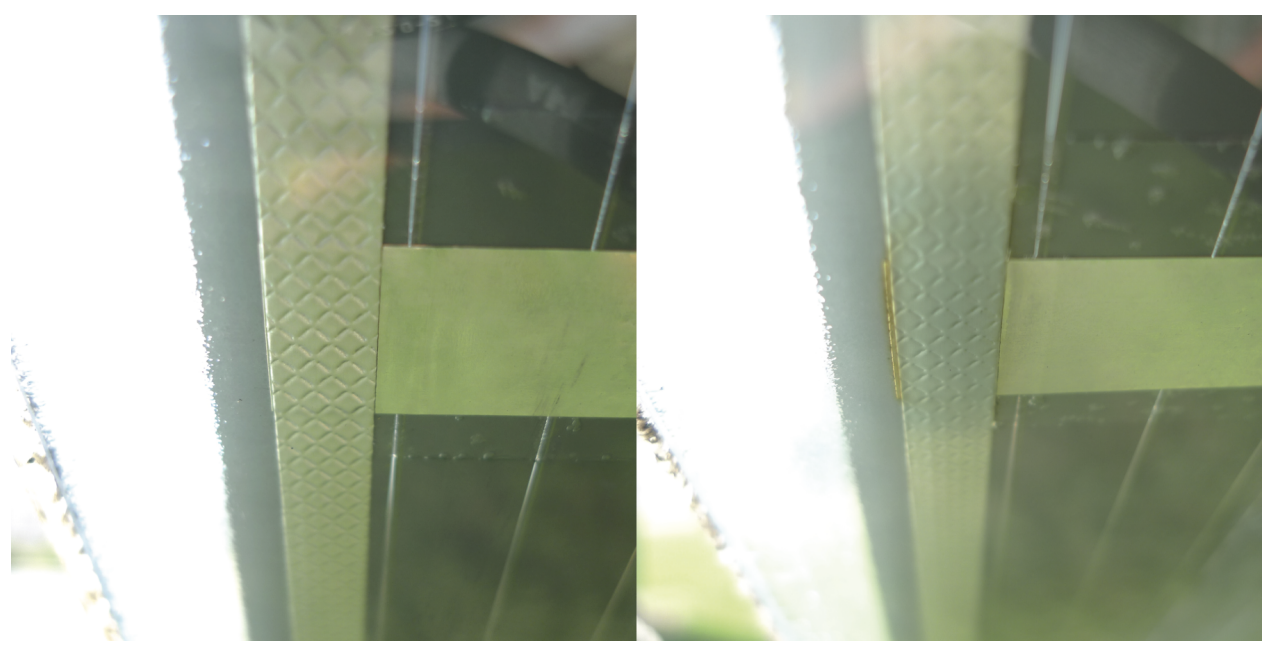

Figure 5: On modules without the type of delamination shown in Figure 4, there was no discoloration at the bus tape intersection (left) but those with the delamination showed brownish discoloration of the encapsulant at this intersection (right).

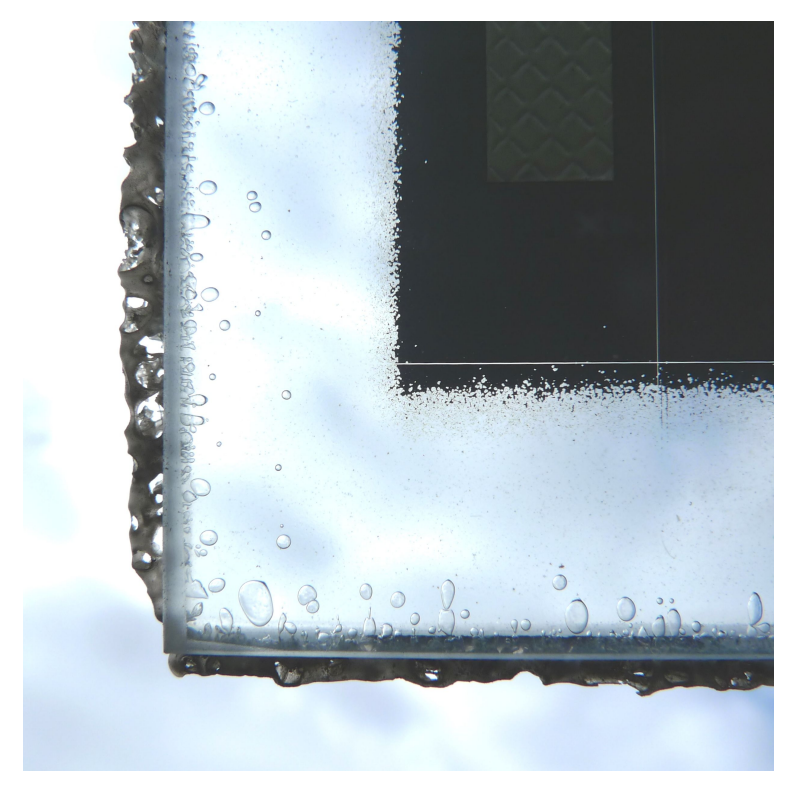

Figure 6: Every module had a porous band of extruded encapsulant around the edge. 


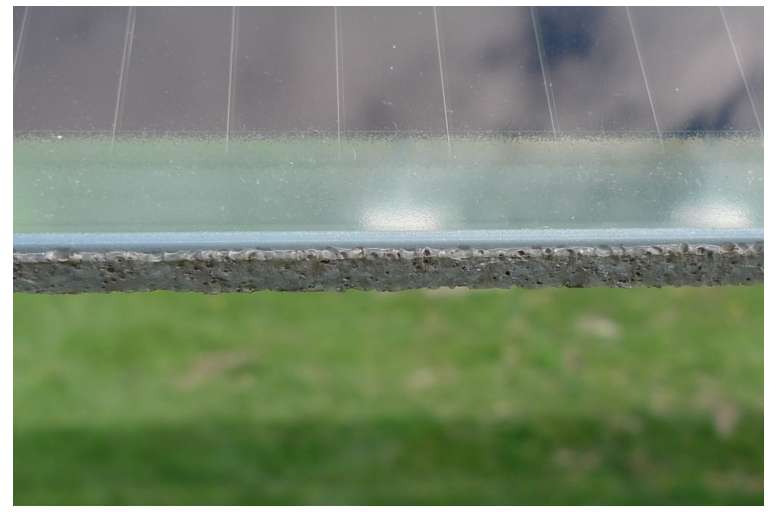

Figure 7: The encapsulant extrudate was nearly the entire thickness of the module and, in many cases, it was artificially flat, suggesting that it did not extrude in the field.

street and sidewalk. The most extreme example is shown in Figure 8. Visible from the back side of the module was brown discoloration presumably due to locally high temperature at areas where the broken glass disturbed interconnection or allowed water ingress.

\subsection{Thermal imaging}

A temperature map of the systems is shown in Figure 9. The map is composed of images collected of each north-south pair of modules. The northernmost modules in each system were necessarily imaged at a shallower angle than the southernmost modules. No correction has been made for sky reflection, so these rows are artificially cooler in the map.

The map shows the bus tape defect on $75 \%$ of modules. Typical modules with bus tape heating show a single spot (Figure 10), while some, such as s4 and h8 (shown in detail in Figure 11), have multiple hot spots along the bus tape. One string of six modules (p7-u7) is hotter than the surrounding modules because the broken module $\mathrm{t}$, shown in Figure 8, places the entire string at open circuit. 


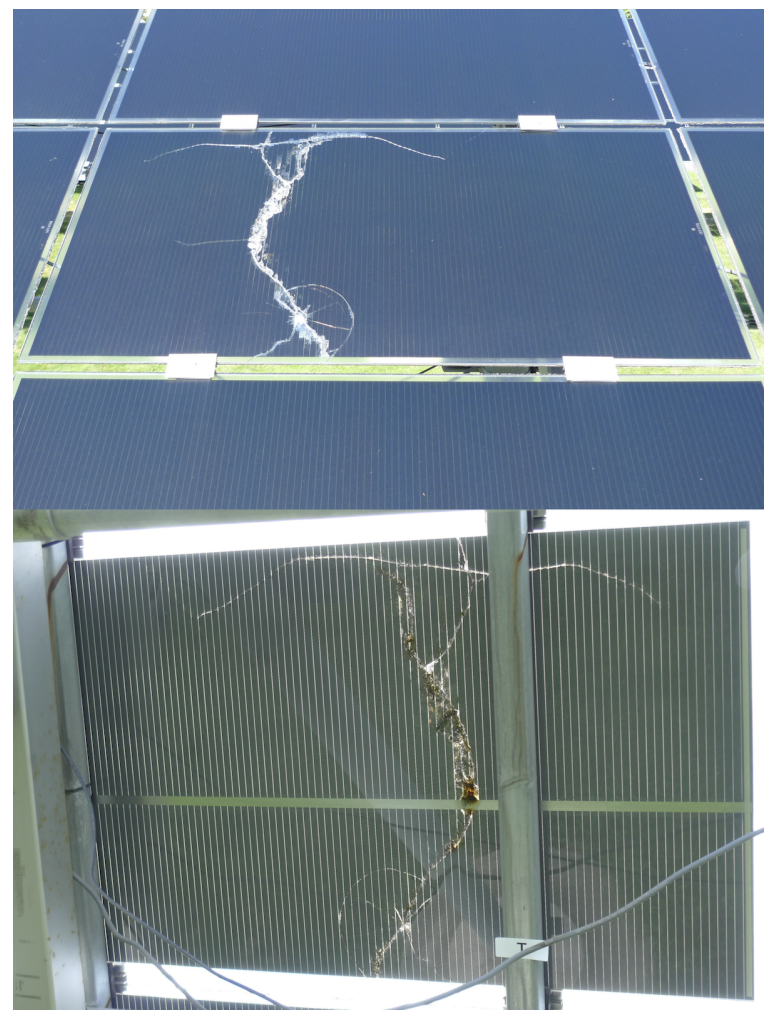

Figure 8: The front (upper image) and back (lower image) sides of a module with broken front glass.

This report is available at no cost from the National Renewable Energy Laboratory (NREL) at www.nrel.gov/publications. 

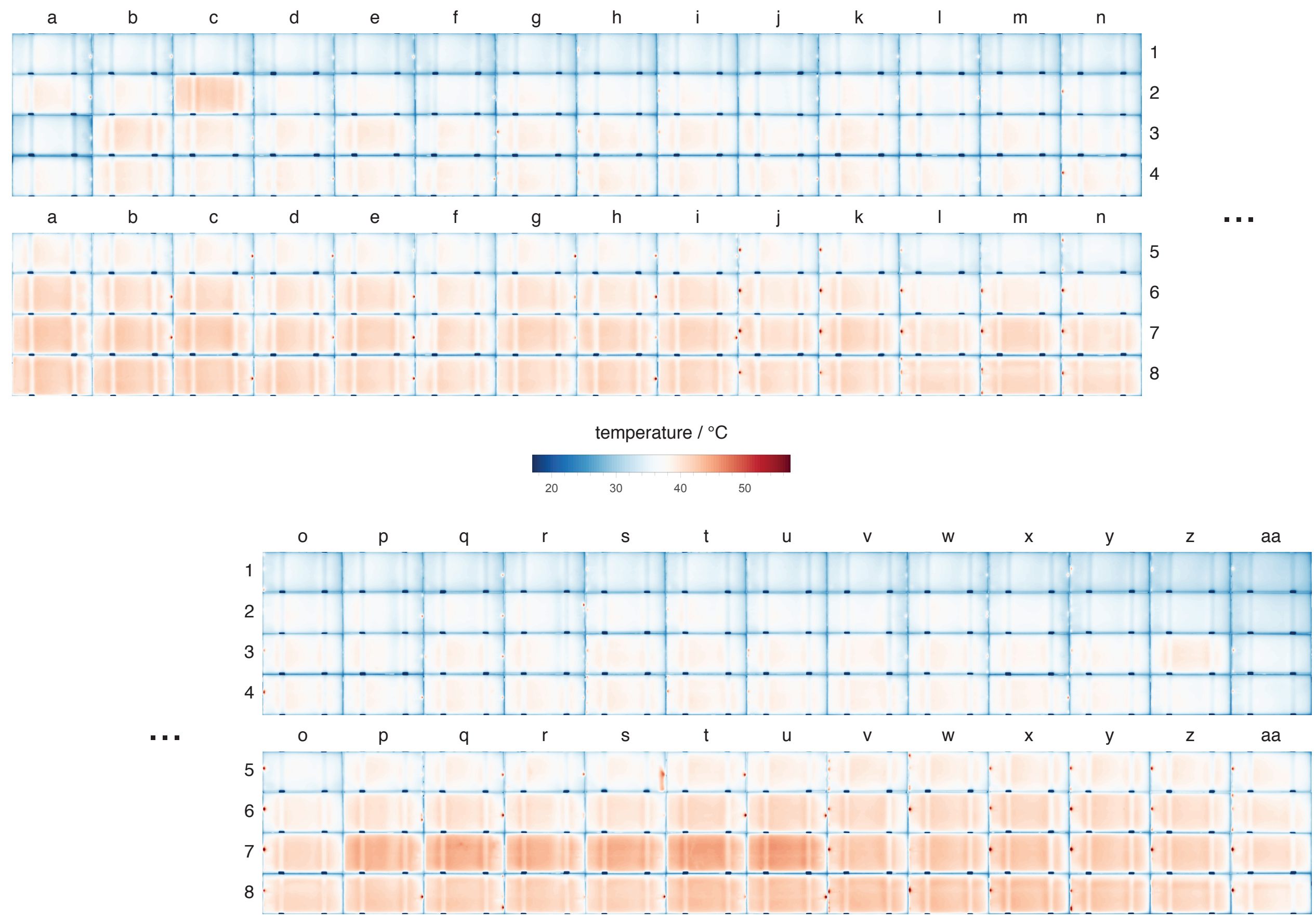

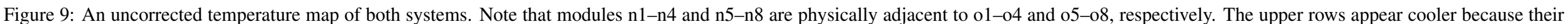
images were collected at a shallower angle.

This report is available at no cost from the National Renewable Energy Laboratory (NREL) at www.nrel.gov/publications. 


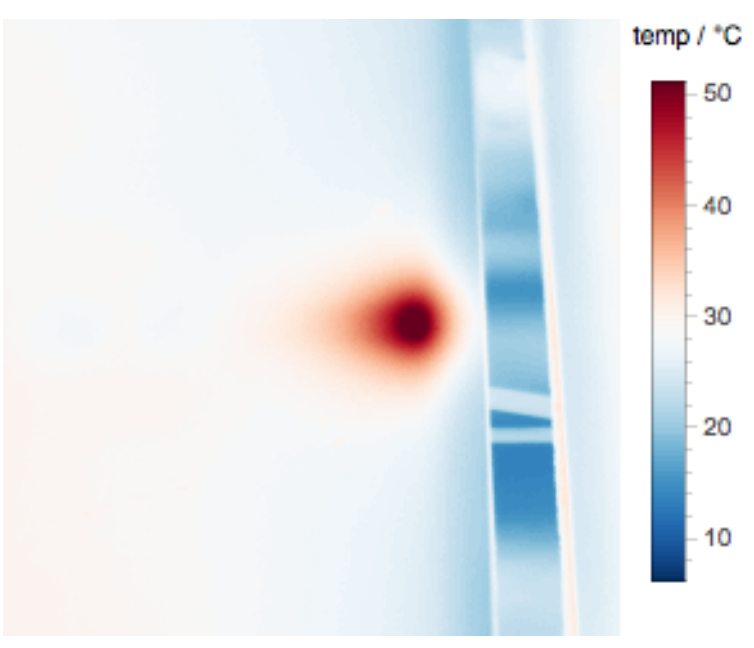

Figure 10: Most modules with bus tape heating show only a single hot area at the intersection of the bus tape. This is over the same area indicated in Figure 4.

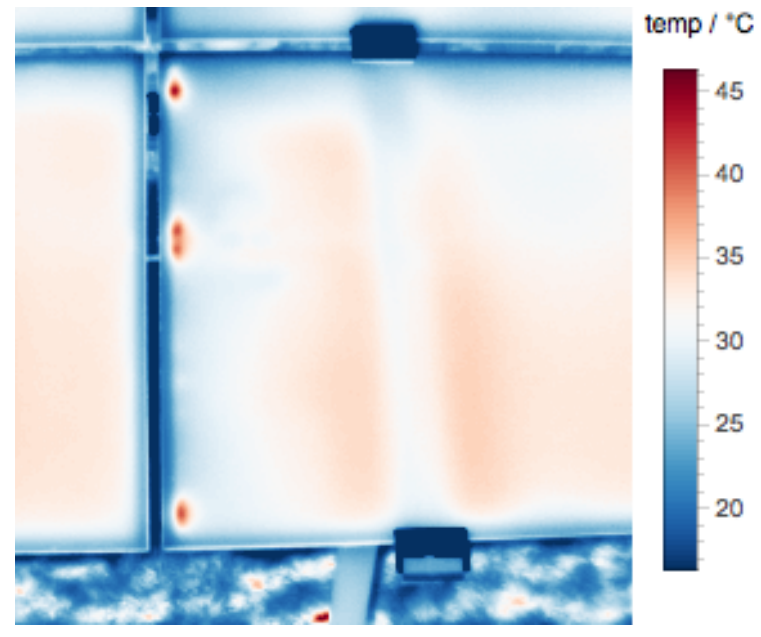

Figure 11: Module h8 is a specimen with multiple hot areas along the bus tape.

\subsection{Electrical characterization}

The performance specifications for model FS-57 are shown in Table 1. We collected light I-V curves outdoors on 42 modules, including one with broken glass which was excluded from further analysis. 24 of the selected modules had bus tape heating and 18 did not; 21 were in the "row 1" system and 21 in the "row 2" system. 
Table 1: Performance specifications for First Solar model FS-57 [1].

\begin{tabular}{rl|cc}
$P_{\mathrm{mp}}$ & $57 \mathrm{~W}$ & $P_{\mathrm{mp}}$ temp. coeff. & $-0.25 \% / \mathrm{K}$ \\
$V_{\mathrm{oc}}$ & $89 \mathrm{~V}$ & $V_{\mathrm{oc}}$ temp. coeff. & $-0.29 \% / \mathrm{K}$ \\
$I_{\mathrm{sc}}$ & $1.13 \mathrm{~A}$ & $I_{\mathrm{sc}}$ temp. coeff. & $0.04 \% / \mathrm{K}$ \\
$V_{\mathrm{mp}}$ & $63 \mathrm{~V}$ & number of cells & 116 \\
$I_{\mathrm{mp}}$ & $0.9 \mathrm{~A}$ & & \\
$F F$ & 0.56 & &
\end{tabular}

We corrected measured power for irradiance and temperature using

$$
P_{\mathrm{mp}, 0}=\frac{E_{0}}{E} \frac{P_{\mathrm{mp}}}{1+\gamma\left(T-T_{0}\right)},
$$

where $P_{\mathrm{mp}, 0}, E_{0}$ and $T_{0}$ are maximum power, irradiance and temperature, respectively, at standard test conditions (STC) of $1000 \mathrm{~W} / \mathrm{m}^{2}$ irradiance and $25^{\circ}$ C. $P_{\mathrm{mp}}, E$ and $T$ are the observed maximum power, irradiance and temperature.

A histogram of corrected power is shown in Figure 12. The median power was $54.8 \mathrm{~W}$, about $4 \%$ below the nameplate power rating, but the sampled population contains a higher fraction of modules free of bus tape heating than the array. Weighting the with-heating power measurements by 0.75 and the without-heating measurements by 0.25 , the mean corrected power was $53.6 \mathrm{~W}$, about $6 \%$ below the nameplate power rating. The median corrected $P_{\mathrm{mp}}$ values for the "row 1" and "row 2" systems were not significantly different.

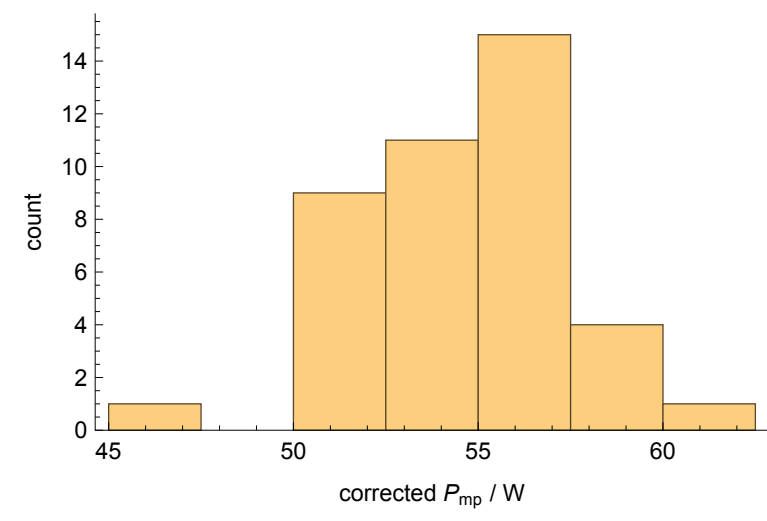

Figure 12: Median corrected $P_{\mathrm{mp}}$ for the 47 sampled modules is about $4 \%$ below the nameplate rating.

A paired histogram of corrected $P_{\mathrm{mp}}$ for modules with and without bus tape heating is shown in Figure 13. The medians were $52.6 \mathrm{~W}$ and $56.7 \mathrm{~W}$, respectively, suggesting the bus tape delamination was responsible for a $4.1 \mathrm{~W}(7 \%)$ reduction in power. The median values of $P_{\mathrm{mp}}$ for the two populations were significantly different according to a Mann-Whitney test $(p<0.001)$. 


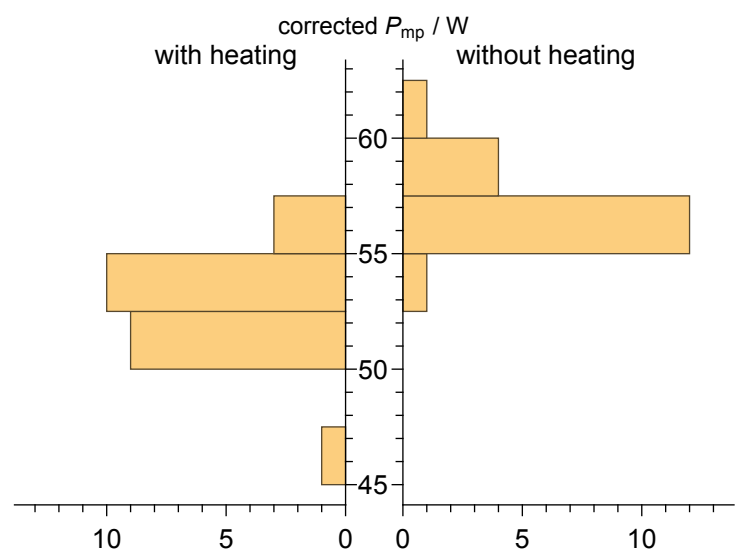

Figure 13: Corrected $P_{\mathrm{mp}}$ for modules with (left) and without (right) bus tape heating. The median $P_{\mathrm{mp}}$ values from these two populations were significantly different.

We fitted each I-V curve using the single diode model [3] to determine each module's series resistance, $R_{s}$. A paired histogram of $R_{s}$ for modules with and without bus tape heating is shown in Figure 14. The medians were $18.3 \Omega$ and $12.7 \Omega$, respectively, suggesting that the bus tape delamination was responsible for a $5.6 \Omega(44 \%)$ increase in series resistance. The median values of $R_{S}$ for the two populations were significantly different according to a Mann-Whitney test $(p<0.001)$.

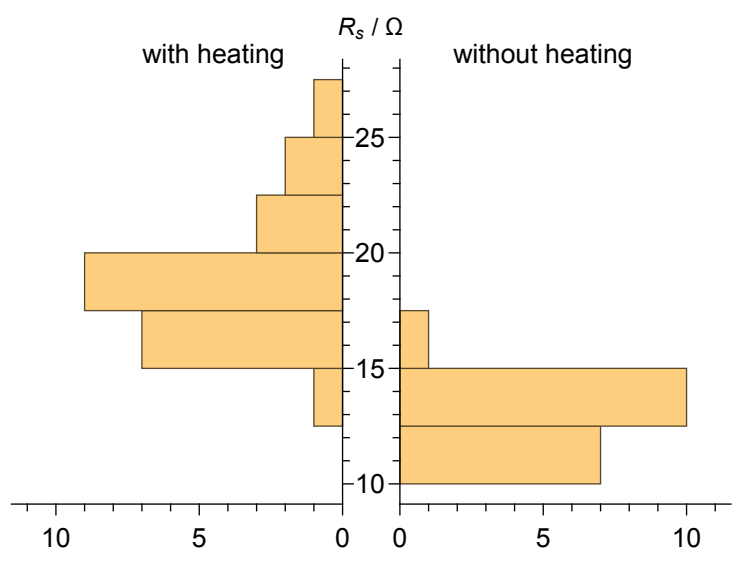

Figure 14: Series resistance $\left(R_{S}\right)$ for modules with (left) and without (right) bus tape heating. The median $R_{S}$ values from these two populations were significantly different.

Table 2 summarizes the performance of the highest- and lowest-power modules we measured. The parameters are temperature- and irradiance-corrected. The $\sim 22 \%$ loss in $P_{\mathrm{mp}}$ is due almost entirely to a loss in $F F$. 
Table 2: Comparison of irradiance- and temperature-corrected performance parameters from the highest- and lowest-power modules we measured.

\begin{tabular}{rllll} 
id & $P_{\mathrm{mp}}(\mathrm{W})$ & $V_{\mathrm{oc}}(\mathrm{V})$ & $I_{\mathrm{sc}}(\mathrm{A})$ & $F F$ \\
\hline h1 & 47.2 & 88.4 & 1.2 & 0.45 \\
f5 & 60.2 & 88.9 & 1.2 & 0.58
\end{tabular}

\section{Conclusion}

We inspected two $6.2 \mathrm{~kW}$ systems of CdTe modules that had been deployed for approximately eight years. Every module displayed some benign defects such as illegible nameplates and extruded encapsulant. Three modules had broken glass and produced little or no power. Approximately $75 \%$ of modules had localized heating at a bus tape intersection near the junction box. This heating was correlated with delamination visible from the front of the module and minor encapsulant discoloration visible from the back. Modules with bus tape heating produced significantly (7\%) less power than those without heating due to significantly $(40 \%)$ higher series resistance. The design of the bus tape has changed substantially in Series 3 First Solar modules, so this problem may have been eliminated. The weighted average corrected $P_{\mathrm{mp}}$ was $53.6 \mathrm{~W}, 6 \%$ below the nameplate rating. Despite never being loaded at $P_{\mathrm{mp}}$ for almost all of the first eight years of its deployment, the "row 2 " system's median $P_{\mathrm{mp}}$ did not differ significantly from that of the "row 1" system.

\section{Acknowledgments}

We gratefully acknowledge the assistance of Randy Ellingson, Mike Heben and Ngalula Sandrine Mubenga at the University of Toledo.

\section{References}

[1] First Solar, Inc. FS-57 data sheet.

[2] Ngalula Sandrine Mubenga. A renewable energy system for fuel cell vehicles. Master's thesis, The University of Toledo, December 2008.

[3] Jenny Nelson. The Physics of Solar Cells. Imperial College Press, 2003.

[4] Corinne E. Packard, John H. Wohlgemuth, and Sarah R. Kurtz. Development of a visual inspection data collection tool for evaluation of fielded PV module condition. Technical Report TP-5200-56154, National Renewable Energy Laboratory, 2012. 